\title{
A SCORING METHOD FOR HESS CHARTS
}

\author{
G. W. AYLWARD, B. McCARRY, L. KOUSOULIDES, J. P. LEE, P. FELLS \\ London
}

\begin{abstract}
SUMMARY
A new scoring system for Hess charts is described. Scores for both horizontal and vertical deviations are calculated from the displacement of individual points on the Hess chart, using weighting factors for the centre, inner and outer zones. The scoring system was validated in a group of 24 patients undergoing surgery for paralytic or restrictive strabismus. Subjective scores were obtained from patients both before and after corrective surgery, and corresponding Hess charts were scored using the new system. There was a good correlation between the changes in subjective and objective score. Our scoring system has applications in both research and clinical practice, allowing objective analysis of changes in muscle balance in a variety of motility disorders.
\end{abstract}

Hess charts provide a useful means of analysing and recording muscle imbalance in patients with diplopia. However, their interpretation is subjective, and comparison between charts may be difficult. An allied, but physiologically different test is the field of binocular single vision. Recently a functional scoring method for it has been introduced, ${ }^{1}$ and subsequently modified. ${ }^{2,3} \mathrm{We}$ describe a new scoring system which allows objective comparisons between Hess charts, and may be useful for sequential examinations of an individual patient, or comparison of different patients with the same disorder.

\section{PATIENTS AND METHODS}

A typical Hess chart for a patient with a superior oblique palsy is shown in Fig. 1. Each point on the chart may be considered to have a horizontal and a vertical displacement from normal (each small square represents 5 degrees). Displacements are always taken as positive, and those that are out of range are assigned an arbitrary maximum displacement of 15 degrees. Simply adding the deviations would give too much importance to the 16 outer points, and not enough to the single central point, which is more clinically significant. Therefore three separate sums, $S_{\mathrm{o}}, S_{\mathrm{i}}$ and $S_{\mathrm{c}}$ are calculated for the 16 outer points, the 8 inner points and the single central point respectively.

Correspondence to: Mr. G. W. Aylward, FRCS, Moorfields Eye Hospital, London ECIV 2PD, UK.
These are then combined according to the following formula:

$$
\text { Score }=F_{\mathrm{o}} S_{\mathrm{o}}+F_{\mathrm{i}} S_{\mathrm{i}}+F_{\mathrm{c}} S_{\mathrm{c}}
$$

where $F_{\mathrm{o}}, F_{\mathrm{i}}$ and $F_{\mathrm{c}}$ are arbitrary weighting factors. We have chosen values of 1,4 and 8 respectively (i.e. the central point is given 8 times the weight of one of the outer points). A total vertical or horizontal score for the patient is then derived by adding the scores for each eye. Both vertical and horizontal scores for a perfectly normal Hess chart should be zero. The calculations involved in deriving the vertical score for the left eye in the Hess chart of Fig. 1 are shown as an example in Table I.

The arithmetic involved in calculating the score for each chart is tedious, but can be simplified with the use of a personal computer. We have written a short program* which allows entry of the Hess chart data using a mouse, or other pointing device, on a graphical representation of the chart (Fig. 2a). The score is then calculated automatically (Fig. 2b).

The scoring system was validated in a group of 24 patients with diplopia who were undergoing surgery for paralytic or restrictive strabismus. Patients were asked to give a subjective assessment of their diplopia using a 10point analogue scale, with zero representing no diplopia. Hess charts recorded at the same time were scored using the new system. Either the vertical or the horizontal score was used according to the greatest degree of diplopia. Both assessments were repeated 2 weeks after surgery. The percentage change of both parameters was calculated and the association between them analysed by deriving Spearman's rank correlation coefficient.

*The program, which runs on an Atari ST personal computer, is public domain and will be supplied free of charge on receipt of a blank, formatted $3 \frac{1}{2}$ inch floppy disk.

Table I. Calculation of the vertical score for the left eye in the Hess chart of Fig. 1

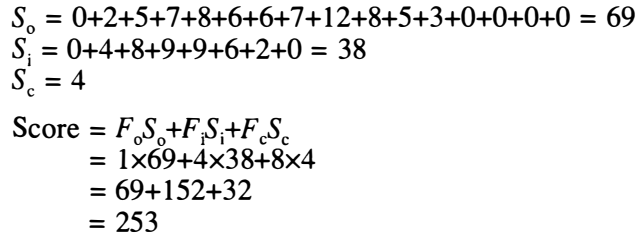




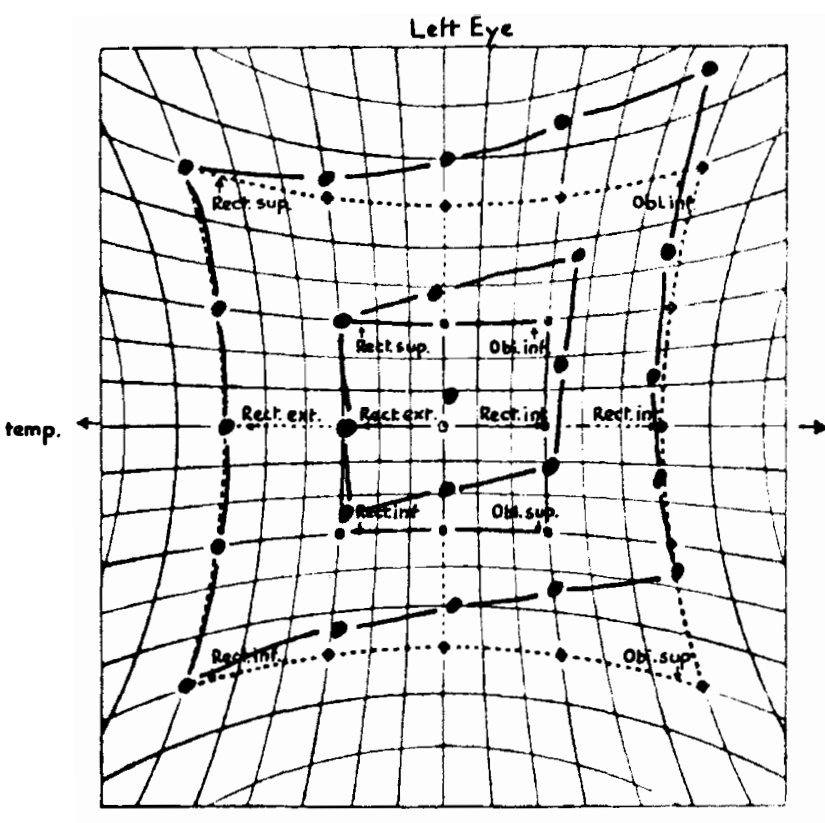

Green before lett eye

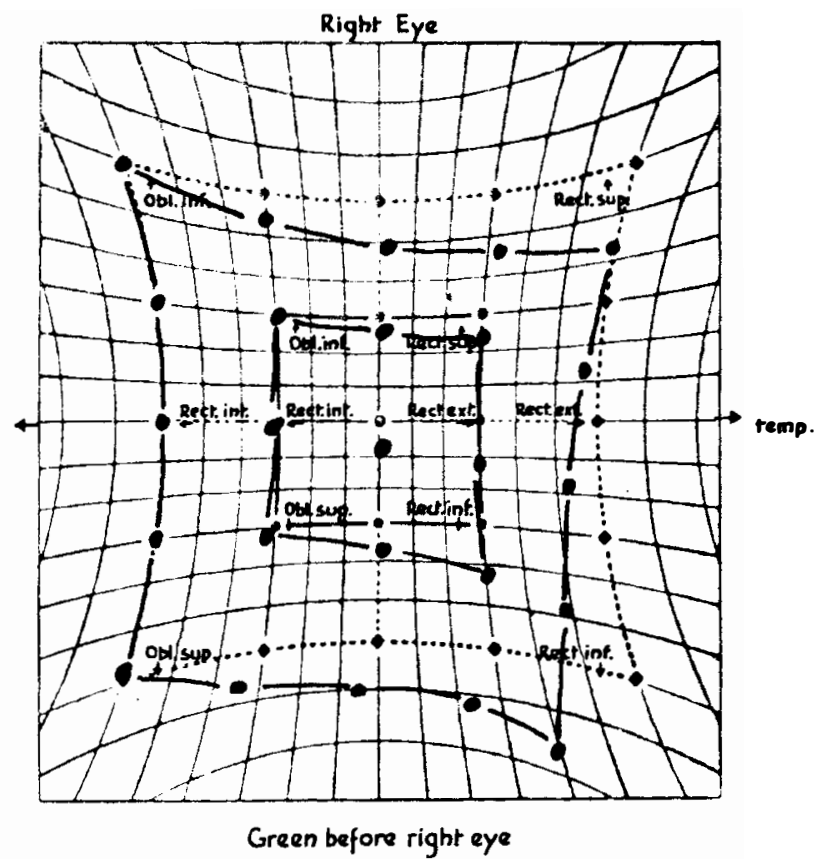

Green before right eye

Fig. 1. Typical Hess chart of a patient with a long-standing left superior oblique palsy.
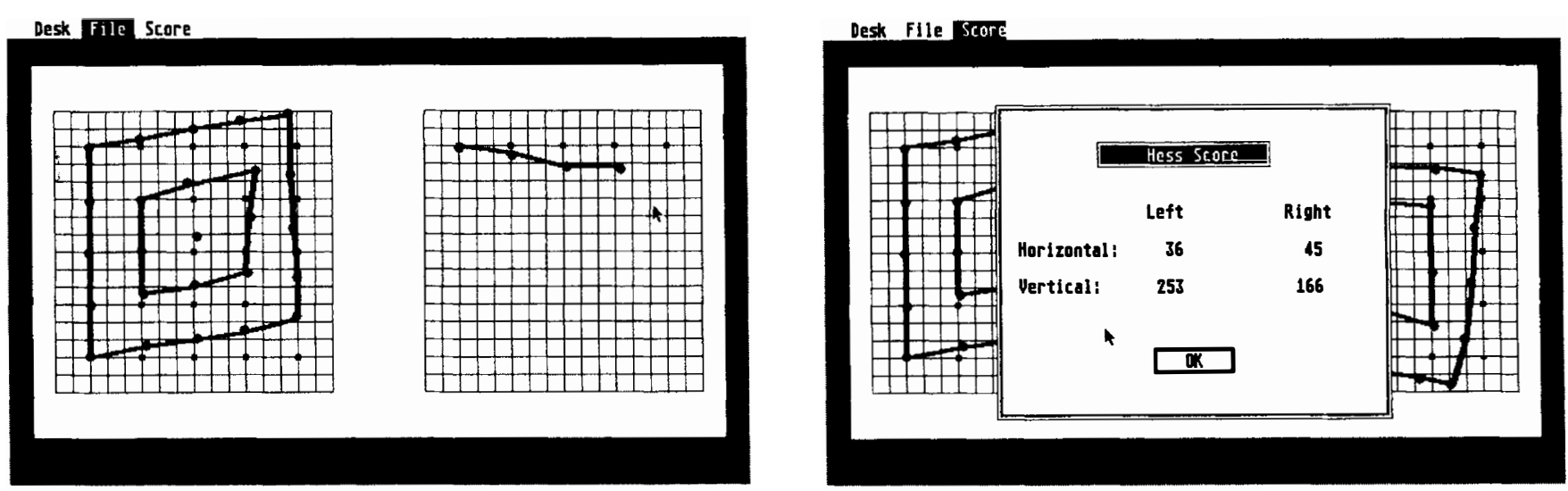

Fig. 2. (a) Computer screen showing entry of Hess chart data using the mouse pointer. (b) The score is generated automatically on completion of data entry.

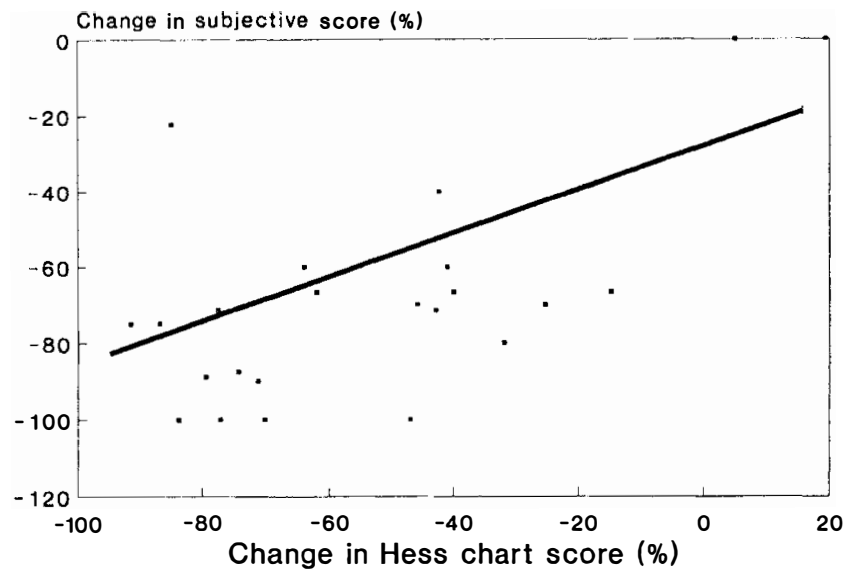

Fig. 3. Scattergram showing the relationship between the percentage change of the subjective and Hess chart scores. $r=0.61, p=0.001$. 
Table II. Diagnosis, subjective scores and Hess scores before and after surgery for 24 patients

\begin{tabular}{|c|c|c|c|c|c|c|}
\hline \multirow[b]{2}{*}{ Patient } & \multirow[b]{2}{*}{ Diagnosis $^{a}$} & \multirow[b]{2}{*}{ Diplopia $^{b}$} & \multicolumn{2}{|c|}{ Pre-operative } & \multicolumn{2}{|c|}{ Post-operative } \\
\hline & & & $\begin{array}{l}\text { Hess } \\
\text { score }\end{array}$ & $\begin{array}{l}\text { Subjective } \\
\text { score }\end{array}$ & $\begin{array}{l}\text { Hess } \\
\text { score }\end{array}$ & $\begin{array}{l}\text { Subjective } \\
\text { score }\end{array}$ \\
\hline 1 & BOF & $\mathrm{h}$ & 467 & 10 & 349 & 3 \\
\hline 2 & BOF & $\mathrm{v}$ & 1131 & 9 & 171 & 7 \\
\hline 3 & BOF & $\mathbf{v}$ & 459 & 9 & 94 & 1 \\
\hline 4 & BOF & $\mathrm{v}$ & 1977 & 8 & 507 & 1 \\
\hline 5 & $\mathrm{BOF}$ & $\mathrm{h}$ & 719 & 6 & 273 & 2 \\
\hline 6 & DED & $\mathrm{v}$ & 2094 & 7 & 1109 & 0 \\
\hline 7 & DED & $\mathrm{v}$ & 1134 & 10 & 614 & 3 \\
\hline 8 & DED & $\mathrm{v}$ & 477 & 10 & 137 & 1 \\
\hline 9 & DED & $\mathrm{v}$ & 1039 & 7 & 168 & 0 \\
\hline 10 & DED & $\mathrm{h}$ & 2387 & 8 & 312 & 2 \\
\hline 11 & Duane's & $\mathrm{h}$ & 2038 & 6 & 1735 & 2 \\
\hline 12 & LRP & $\mathrm{h}$ & 529 & 2 & 555 & 2 \\
\hline 13 & LRP & $\mathrm{h}$ & 450 & 6 & 148 & 2 \\
\hline 14 & LRP & $\mathrm{h}$ & 985 & 8 & 83 & 2 \\
\hline 15 & SOP & $\mathrm{v}$ & 544 & 7 & 311 & 2 \\
\hline 16 & SOP & $\mathrm{v}$ & 671 & 10 & 153 & 0 \\
\hline 17 & SOP & $\mathrm{v}$ & 1448 & 5 & 522 & 2 \\
\hline 18 & SOP & $\mathrm{v}$ & 446 & 7 & 100 & 2 \\
\hline 19 & SOP & $\mathrm{h}$ & 60 & 6 & 36 & 2 \\
\hline 20 & SOP & $\mathrm{v}$ & 452 & 5 & 267 & 2 \\
\hline 21 & SOP & $\mathrm{v}$ & 739 & 10 & 503 & 2 \\
\hline 22 & SOP & $\mathrm{h}$ & 855 & 5 & 1020 & 5 \\
\hline 23 & SOP & $\mathrm{v}$ & 467 & 6 & 139 & 0 \\
\hline 24 & SOP & $\mathrm{v}$ & 1426 & 10 & 823 & 6 \\
\hline
\end{tabular}

${ }^{a} B O F$, blow-out fracture; DED, dysthyroid eye disease; LRP, lateral rectus palsy; SOP, superior oblique palsy.

${ }^{b} h$, horizontal diplopia; v, vertical diplopia.

\section{RESULTS}

Figure $2 \mathrm{~b}$ shows the scores for the Hess chart illustrated in Fig. 1. Note that the total vertical score is much larger, reflecting the greater disturbance in vertical muscle balance in superior oblique palsy. Table II shows the diagnosis, subjective scores and Hess scores, both before and after surgery for the 24 patients. Twenty-two noted an improvement in their symptoms following surgery, which was reflected in a decrease in their subjective score. The remaining two (patients 12 and 22) did not change their subjective score post-operatively. The relationship between the percentage change in the subjective score and the percentage change in the Hess chart score is shown in Fig. 3. Spearman's rank correlation coefficient was 0.51 ( $p=0.01,95 \%$ confidence interval 0.13 to 0.76 ).

\section{DISCUSSION}

The percentage change in the Hess chart score agrees reasonably well with the change in the patient's subjective assessment. The direction of change of both measures was the same in all cases except two, where no change in the subjective score was associated with small increases in the Hess chart score. The rank correlation coefficient describes an overall association, and compares favourably with that derived for functional scoring of the field of binocular single vision. ${ }^{2}$ This helps to validate the new scor- ing system as a measure of change in an individual patient. Scores can also be used to compare different patients with the same condition, but comparison between different forms of strabismus would not be meaningful. We have used the scoring system successfully to analyse the results of surgery and post-operative progress in a group of patients with traumatic Brown's syndrome. ${ }^{4}$

The scoring method described provides a simple, reproducible, objective and quantitative assessment of disorders of muscle balance in patients with diplopia. The scoring system should have applications in both research and clinical practice, allowing objective analysis of Hess charts in a variety of motility disorders.

\section{REFERENCES}

1. Woodruff G, O'Reilly C, Kraft SP: Functional scoring of the field of binocular single vision in patients with diplopia. Ophthalmology 1987, 94: 1544-61.

2. Fitzsimmons R and White J: Functional scoring of the field of binocular single vision. Ophthalmology 1990, 97: 33-5.

3. Sullivan TJ, Kraft SP, Burack C, O'Reilly C: A functional scoring method for the field of binocular single vision. Ophthalmology 1992, 99: 575-81.

4. Aylward GW, Lawson J, McCarry B, Lee JP, Fells P: The surgical treatment of traumatic Brown syndrome. $J$ Paediatr Ophthalmol Strabismus (in press). 